\title{
Active Synchronous Control Strategy of Distributed Power Grid Connection Based on Mobile Network
}

\author{
Liu Zhang $\left(\mathbb{D},{ }^{1,2}\right.$ Shaohua Ma $\mathbb{D},{ }^{1}$ Yangyang Ge, ${ }^{3}$ Cailian $\mathrm{Gu}^{2}$ and Hao Wang ${ }^{4}$ \\ ${ }^{1}$ School of Electrical Engineering, Shenyang University of Technology, Shenyang 110023, Liaoning, China \\ ${ }^{2}$ School of Electric Power, Shenyang Institute of Engineering, Shenyang 110036, Liaoning, China \\ ${ }^{3}$ Distribution Network TechnologyCenter, Liaoning Electric Power Research Institute, Shenyang 110023, Liaoning, China \\ ${ }^{4}$ School of Renewable Energy, Shenyang Institute of Engineering, Shenyang 110036, Liaoning, China \\ Correspondence should be addressed to Shaohua Ma; mash_dq@sut.edu.cn
}

Received 1 December 2020; Revised 16 February 2021; Accepted 3 April 2021; Published 17 April 2021

Academic Editor: Xiaoxian Yang

Copyright (C) 2021 Liu Zhang et al. This is an open access article distributed under the Creative Commons Attribution License, which permits unrestricted use, distribution, and reproduction in any medium, provided the original work is properly cited.

\begin{abstract}
This paper presents an active synchronous control scheme for distributed power grid connection based on the mobile network. This scheme avoids the disadvantages of the traditional control method, such as long waiting time and low reliability, and can meet the requirements of "the hotplug online" distributed power grid connection. The scheme uses the mobile network to collect and detect voltage slip information between the distributed power system and large power grid before operation. When the voltage slip cannot meet the requirements of grid connection, the side voltage information of the distributed power system is actively regulated. The amplitude difference and phase difference signals are, respectively, adjusted by PI, and the generated adjustment signals are, respectively, sent to the corresponding controllers through the mobile network with different weight coefficients. After the receiver receives the regulated signal, it changes the amplitude and frequency of its output voltage by shifting the pendent characteristic curve, so as to realize the distributed power system side voltage and the large power grid side voltage eventually. Finally, simulation analysis and experiments are used to verify the effectiveness and practicability of the active synchronous control strategy.
\end{abstract}

\section{Introduction}

The distributed power system is connected with the large power grid under normal conditions. When the fault of the large power grid is detected, the distributed power system can be separated from the large power grid in time to enter the off-grid independent operation state. Whether in the grid-connected operation or off-grid operation, it is necessary to coordinate and control the distributed power system and other distributed power sources and energy storage equipment to ensure the stability of the system $[1,2]$.

Due to the transition between the grid-connected and off-grid state of the distributed generation system, a large amount of information with random fluctuation and intermittence is involved. Accurate grid-connection operations are also limited by the capacity of the communication network and data processing capacity. If the measuring equipment involving massive information cannot realize timely interconnection with the upper power grid dispatching, it will directly lead to the failure of the gridconnected and off-grid operation of the distributed generation system. The measurement terminals participating in the distributed generation system and off-grid operation are widely distributed, and most of the capacity is relatively small. Traditional optical fiber private network, wireless private network, and other communication methods are high cost, and the number of connections is limited [3-5]. Therefore, the advantages of large connection provided by the mobile network can be utilized to improve the quantity and cost performance of measurement terminal access. The literature [6] proposes a scheduling algorithm. The algorithm first divides the tasks into different levels according to the topology structure, and then three strings are used to encode the genes in the algorithm in order to better reflect the heterogeneity and elasticity of the cloud environment. Finally, HEFT is used to generate the individuals with the 
minimum completion time and cost. The literature [7] analyzes the access and connectivity probability between the vehicles and the road side units (RSUs) of the multiway platoon-based VANETs with roadside infrastructure. The paper denotes the connectivity probability as the probability that the vehicles on the highway can access to at least one RSU besides the road within a designated number of hops. Moreover, besides considering the connection on the same road, the connection between the vehicles and the RSU via vehicles on the nearby neighbor roads are studied. The literature [8] proposes the periodic trends of users' consuming behavior from historical records by KNN (K-nearest neighbor) and SVR (support vector regression) based time series prediction. It provides a highly personalized and accurate marketing method for a large number of items and limited mobile devices.

On the basis of the above research, this paper designs a grid-connected operating system of the distributed generation system based on the mobile network, aiming at the problems of low mass information access rate, poor stability, and high delay in the control system of grid-connected operation of the distributed generation system $[9,10]$. By taking advantage of the characteristics of the mobile network with low delay and large connection, the parameters related to the grid-connection operation of the distributed generation system, including collaborative perception, collection of monitored objects in the monitoring area, and other information, can be fully accessed. And the information will be transmitted or uploaded to the background management system in the region. Real-time monitoring of the distributed transmission system is realized to facilitate rapid maintenance and off-grid control operations in case of failure.

\section{Materials and Methods}

2.1. Overall Framework of Data Acquisition System. In this paper, the system architecture diagram as shown in Figure 1 is designed for the data acquisition of both sides of the gridconnected switch in the distributed generation system. The system uses the WCDMA network to collect the data on both sides of the grid-connected switch. At the same time, the data are transmitted and processed in real time through the WCDMA network. Finally, the data are transmitted to the control system of the interface inverter.

As shown in Figure 1, the data acquisition system mainly includes three levels: data acquisition layer, data processing layer, and data central processing layer [11, 12]. The data acquisition layer is used to collect the on-site data of the switch. The collected data are transmitted to the central control room through the WCDMA network, so as to carry out the relevant operation on the data, for example, data query, storage, processing, and display; data processing layer, mainly including data preprocessing operations, such as data cleaning, conversion, and loading operations.

2.1.1. WCDMA Network Architecture. The data acquisition system of grid-connected switch based on WCDMA is composed of central control room, data acquisition device, WCDMA communication module, etc., as shown in Figure 2.

In the WCDMA network system, MSC and VLR are generally used in combination, and both are implemented on the same physical network entity [13-15]. MSC is similar to the brain of the whole network call control, and its main function is to decide how to handle the call control process of the user devices under its control, as well as to manage the mobility of the user devices $[16,17]$. In addition, MSC/ VLR also complete authentication and encryption functions. GMSC is the gateway node between the circuit switching domain of the WCDMA mobile network and the external network $[18,19]$. The main function of GMSC is to act as a mobile gateway between the mobile network and fixed network and to complete the routing function of inbound calls when PSTN users call mobile users. SGSN performs mobility management, security management, access control, and routing functions. GGSN is responsible for providing the interface between the GPRS PLMN and the external packet data network and providing the necessary internetwork security mechanism. The main function of HLR is to store the user's contract information, support new business, and authentication [20-23]. The AUC is the functional entity responsible for generating the corresponding authentication parameters in the authentication center.

2.1.2. Data Transmission and Processing Strategy. The scheme adopted in this paper is stochastic linear network coding. When User 1 needs to share file $M$ with other users, first of all, it needs to divide file $M$ into $P$ parts $\left(m_{1}, m_{2}, m_{3}, \ldots, m_{p}\right)$ [24-26]. When user 1 receives file requests from other users, a new file will be generated and sent to the requester after recoding $p$ file slices locally:

$$
K_{\text {new }}=\left[a_{1}, a_{2}, \ldots, a_{p}\right]\left[m_{1}, m_{2}, \ldots, m_{p}\right]^{T}=\sum_{i=1}^{p} a_{i} * m_{i} \text {, }
$$

where $\left[a_{1}, a_{2}, \ldots, a_{p}\right]$ is the $p$-dimensional coding vector randomly selected on the finite field GF (256).

When the recencoded data $K_{\text {new }}$ are obtained, values and random encoding vectors are required to be concatenated in front of the encoded data for decoding. After encapsulation, the data transmitted in the network are $X_{i}=\left[P, a_{i 1}, a_{i 2}, \ldots, m_{i}\right]$. 


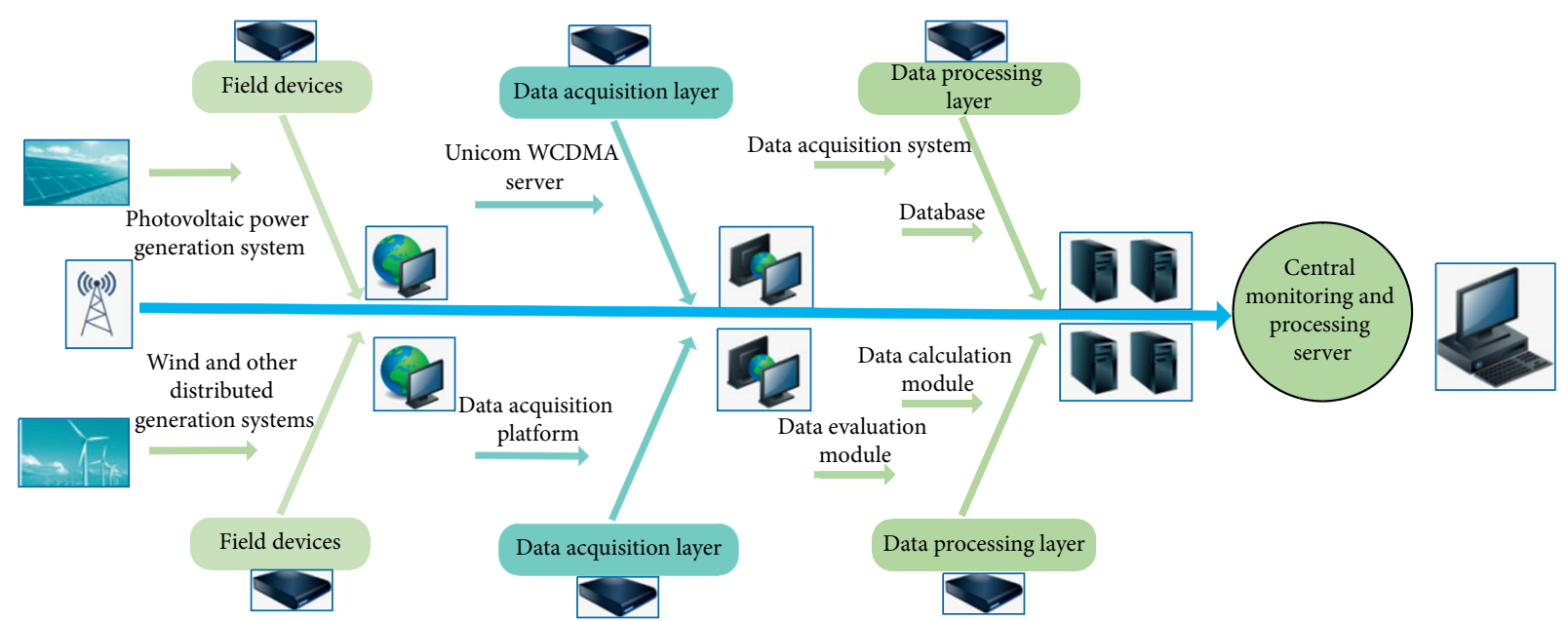

FIgURe 1: Data acquisition system architecture.
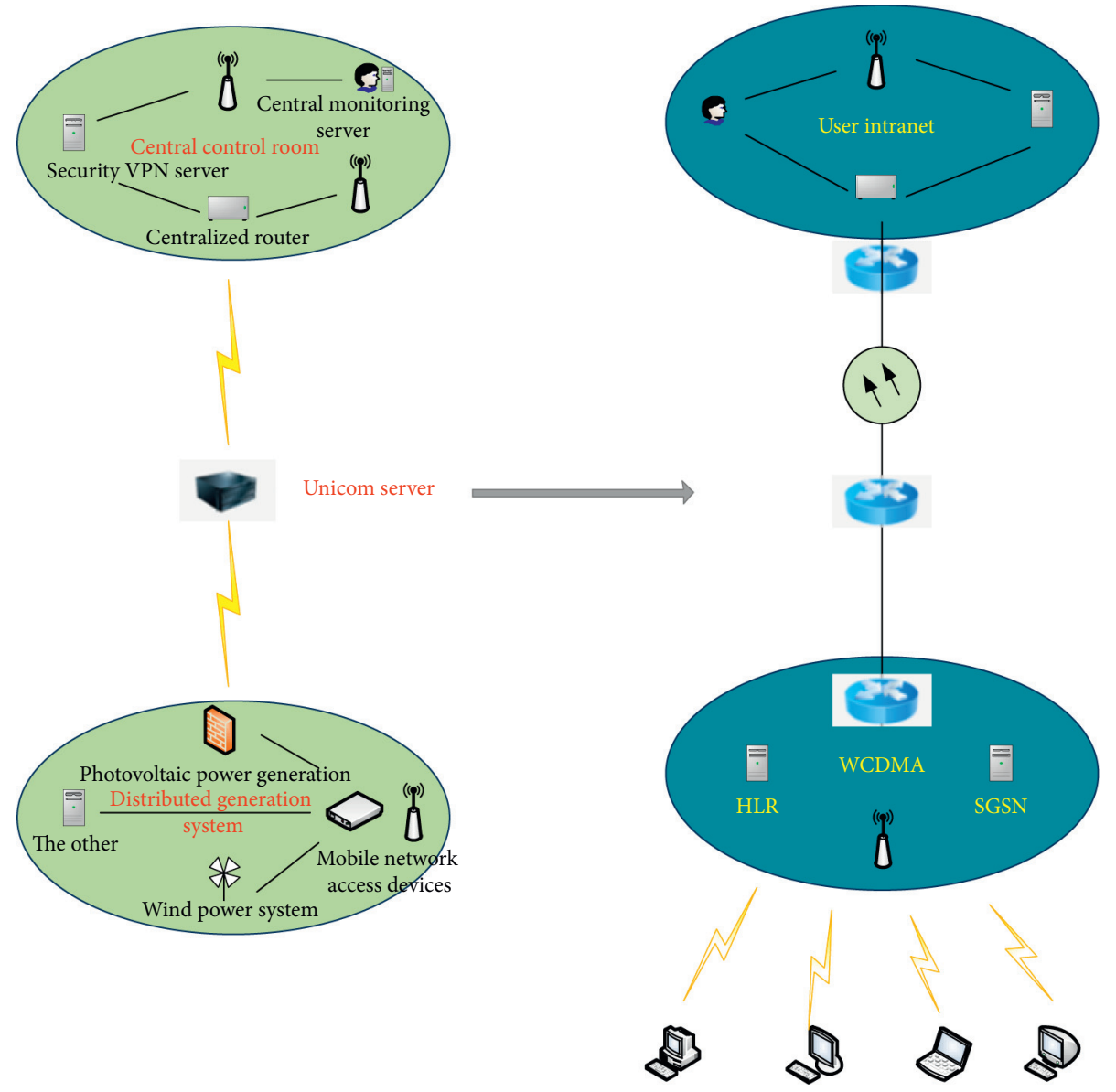

Figure 2: Mobile network data acquisition system construction diagram. (a) Overall framework. (b) Specific form of construction. 


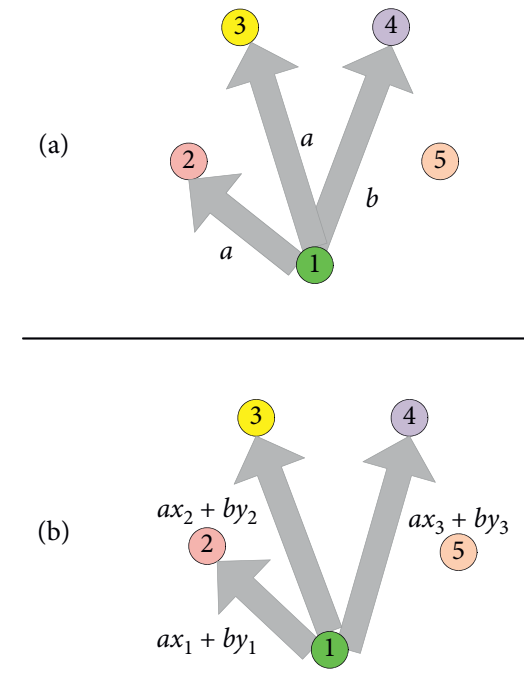

Stage A $+b y_{3}$

$a x_{1}+b y_{1}$
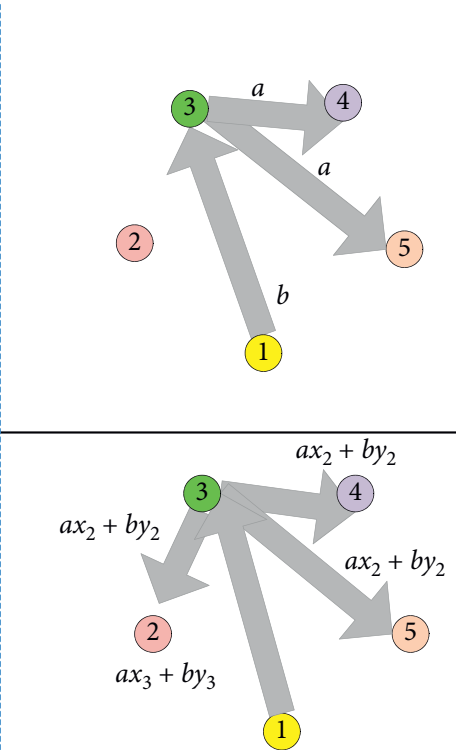

Stage B

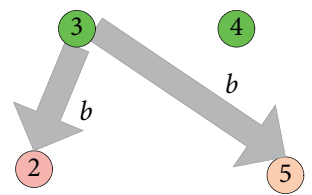

(1)

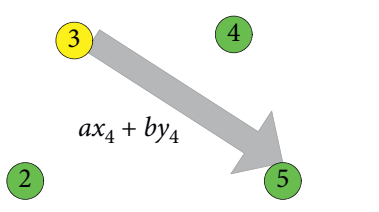

(1)

Stage C

Figure 3: Network coding mode of the mobile network.

When intermediate node 2 receives $P_{i}\left(P_{i} \geq P\right)$ data, it can switch to AP mode. Once a file request is received, node 2 will randomly select $P_{i}$ encoding vectors to encode locally owned data and send it to the requester.
When a user receives $P$ linearly independent pieces of data, he can use the formula to decode the original file [27, 28]. First, extract the $P * P$ coding matrix $A$ from the coding file $X$, and find the inverse matrix of $A^{-1}$. Then, $A^{-1}$ multiplied by $X$ will restore the original file $M$ :

$$
A^{-1} X=\left[\begin{array}{cccc}
a_{(j 1) 1} & a_{(j 1) 2} & \cdots & a_{(j 1) P} \\
a_{(j 2) 1} & a_{(j 2) 2} & \cdots & a_{(j 2) P} \\
\vdots & \vdots & \ddots & \vdots \\
a_{(j P) 1} & a_{(j P) 2} & \cdots & a_{(j P) P}
\end{array}\right]^{-1}\left[\begin{array}{llll}
X_{j 1} & X_{j 2} & \cdots & X_{j P}
\end{array}\right]^{T}=\left[\begin{array}{ccccc}
1 & 0 & \cdots & 0 & m_{1} \\
0 & 1 & \cdots & 0 & m_{2} \\
\vdots & \vdots & \ddots & \vdots & \vdots \\
0 & 0 & \cdots & 1 & m_{P}
\end{array}\right]=[E \mid P] .
$$

Once a user has obtained all the data and decoded the original data, it can switch to AP mode and become the new data source to send data to other users $[29,30]$.

Figure 3 shows the difference between a file-sharing network based on network coding and a traditional copybased scheme. In Figure 3(a), device 1 (the file owner) needs to send two pieces of data (A and B) to each device in the network. In the first phase, device 1 randomly selects one data from data $\mathrm{A}$ and $\mathrm{B}$ to send to adjacent devices (devices 2,3 , and 4 ). When devices 2,3 , and 4 receive all the data, they switch to AP mode and only need to forward the received data to the neighboring nodes. However, in Figure 3(b), device 1 sends data of different linear combinations to neighboring nodes, and when these neighboring nodes are in AP mode, the linear combination data will also be sent to their neighboring devices. For example, device 3 sends a new linear combination of data to device 5 . In Figure 3(b), in the third phase, we observe that devices 2 and 5 have all the data. However, in Figure 3(a), devices 2 and 5 receive only partial data. It can be seen that the scheme using network coding has higher sharing efficiency. In Figure 3, there are only five devices and the network transmits a maximum of two hops. In experimental scenarios with more devices, each device will switch to AP mode after receiving partial data, which is more conducive to sharing files among a large number of devices. Through the multiple relay data of the network equipment, the coverage of the network has been greatly expanded.

\subsection{Active Synchronization Control Strategy}

2.2.1. Slip Signal Detection. Slip signal is an important index for the central controller to determine whether the distributed power system side voltage information meets the grid-connection standard. As the most commonly used slip signal detection method, the zero-crossing detection method is simple in principle and easy to implement, but it has the 
disadvantages of long detection time and weak anti-interference ability [31, 32].

To overcome these shortcomings, experts at home and abroad have studied the improvement of the slip signal detection method:

(1) Modified zero-crossing detection scheme: the voltage sampling curve is fitted by polynomial. Under stable state, the accurate frequency tracking is realized, but the anti-interference ability is weak $[1,14,33]$.

(2) The scheme based on discrete Fourier transform has strong antiharmonic interference ability. However, due to the complexity of calculation, long operation time, and fast frequency change, the slip signal error is relatively large [34, 35].

This paper presents a fast and effective slip signal detection method. By converting A, B, and C three-phase voltage signals to the two-phase synchronous rotating coordinate system, the amplitude difference, phase difference, and frequency difference between the voltage on both sides of the distributed power system and large power grid can be obtained quickly and accurately through simple and effective calculation [36-38].

Assuming that both sides of the distributed power system and the large power grid are ideal balanced threephase sinusoidal AC voltage, its expression is as follows:

$$
\begin{aligned}
& {\left[\begin{array}{l}
U_{a} \\
U_{b} \\
U_{c}
\end{array}\right]=\left[\begin{array}{c}
U \cos (\omega t) \\
U \cos \left(\omega t-120^{\circ}\right) \\
U \cos \left(\omega t+120^{\circ}\right)
\end{array}\right],} \\
& {\left[\begin{array}{l}
V_{a} \\
V_{b} \\
V_{c}
\end{array}\right]=\left[\begin{array}{c}
V \cos \left(\omega t-\theta_{0}\right) \\
V \cos \left(\omega t-120^{\circ}-\theta_{0}\right) \\
V \cos \left(\omega t+120^{\circ}-\theta_{0}\right)
\end{array}\right] .}
\end{aligned}
$$

According to coordinate transformation, the voltage information of both sides is converted to the same rotating coordinate system. The DQ axis components of the voltage on both sides of the distributed power system and the large power grid are, respectively,

$$
\begin{aligned}
& {\left[\begin{array}{l}
U_{d} \\
U_{q}
\end{array}\right]=\left[\begin{array}{l}
U \cos \left(\omega t-\theta_{t}\right) \\
U \sin \left(\omega t-\theta_{t}\right)
\end{array}\right]=\left[\begin{array}{l}
U \\
0
\end{array}\right],} \\
& {\left[\begin{array}{l}
V_{d} \\
V_{q}
\end{array}\right]=\left[\begin{array}{l}
V \cos \left(\omega_{v v} t-\theta_{t}-\theta_{0}\right) \\
V \sin \left(\omega_{v v} t-\theta_{t}-\theta_{0}\right)
\end{array}\right] .}
\end{aligned}
$$

In order to facilitate the calculation of voltage slip, assume that the large grid voltage vector is $U \angle 0^{0}$, angular frequency is $\omega$, distributed power system voltage vector is $V_{1}<-\theta_{0}$, and angular frequency is $\omega_{1}[9,39,40]$. The general voltage vector diagram is shown in Figure 4, where the voltage rotates counterclockwise.

According to the DQ axis components of the voltage on both sides, the amplitude difference, phase difference, and frequency difference can be calculated as follows:

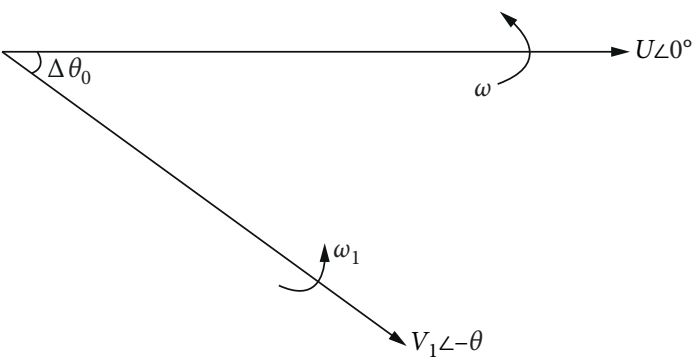

FIgURE 4: General vector diagrams for large power grids and distributed power systems.

$$
\left\{\begin{array}{l}
\Delta v=\sqrt{U_{d}^{2}+U_{c}^{2}}-\sqrt{V_{d}^{2}+V_{c}^{2}}, \\
\Delta \theta=\tan ^{-1} \frac{U_{c}}{U_{d}}-\tan ^{-1} \frac{V_{c}}{V_{d}} \\
\Delta \omega=\frac{d(\Delta \theta)}{d t}
\end{array}\right.
$$

2.2.2. The Design of Active Synchronous Control Strategy. Active current and reactive current output by multiple inverters is controlled by adjusting the amplitude and frequency of the output voltage. The adjustment process is completed, and the new stable operation state is reached. At this point, the active and reactive currents can be evenly divided. The specific expression is as follows:

$$
\left\{\begin{array}{l}
E=E^{\prime}-L\left(I_{d k}-I_{d k}^{\prime}\right), \\
\omega=\omega^{\prime}-K\left(I_{q k}-I_{q k}^{\prime}\right) .
\end{array}\right.
$$

If the droop coefficient of multiple inverters meets the inversely proportional relationship with their capacity in the case of isolation, the current can be distributed proportionally according to their capacity. Set the inverter capacity ratio as $n$, and then

$$
\left\{\begin{array}{l}
\frac{L_{1}}{L_{2}}=\frac{I_{d 2}}{I_{d 1}}=\frac{I_{1 . d 2}}{I_{2 \cdot d 1}}=\frac{1}{n} \\
\frac{K_{1}}{K_{2}}=\frac{I_{q 2}}{I_{q 1}}=\frac{I_{1 . q 2}}{I_{2 . q 1}}=\frac{1}{n} .
\end{array}\right.
$$

The expressions of active and reactive power circulation for parallel systems of inverters with different capacities are shown as follows:

$$
\left\{\begin{array}{l}
I_{d K}=I_{d 1}-n I_{d 2}=\frac{E_{1} \cos \phi_{1}}{r_{1}-n * E_{2} \cos \phi_{2} / r_{2}}-\frac{U}{r_{1}-n * U / r_{2}}, \\
I_{q K}=I_{q 1}-n I_{q 2}=\frac{-E_{1} \sin \phi_{1}}{r_{1}+n * E_{2} / r_{2}} .
\end{array}\right.
$$

In addition, 


$$
\left\{\begin{array}{l}
I_{d \mathrm{~K}}=\frac{\left[\left(E_{K} \cos \phi_{K}-U\right) \cos \phi_{K}+E_{K} \sin \phi_{K} \cos \phi_{K}\right]}{Z_{K}}, \\
I_{q K}=\frac{-\left[\left(E_{K} \cos \phi_{K}-U\right) \sin \phi_{K}-E_{K} \sin \phi_{K} \cos \phi_{K}\right]}{Z_{K}} .
\end{array}\right.
$$

The output voltage of the inverter can be obtained by combining equations (7) and (10):

$$
E_{K}=\frac{E_{K}^{\prime}\left(r_{K} / L_{K}\right)+U+r_{K} I_{d K}^{\prime}}{\left(r_{k} / L_{K}\right)+\cos \phi_{K}} .
$$

According to equation (10), it is necessary to eliminate voltage deviation in steady state, and the sag coefficient is inversely proportional to the capacity. Therefore, there is $n * r_{1}=r_{2}$.

According to the above analysis, considering from the perspective of circulation, the equivalent impedance of the system is inversely proportional to the capacity of the inverter, which can realize the parallel connection of inverters with different capacity to distribute the load accurately and proportionally according to the capacity.

Due to the integration link in droop control, the frequency of the system will automatically synchronize when it reaches steady state. Here,

$$
\omega_{1}=\omega_{2}=\cdots=\omega_{K}=H .
$$

Combined with the current droop governing equation, it can be obtained as follows:

$$
K_{1} *\left(I_{q 1}-I_{q 1}^{\prime}\right)=\omega_{1}^{\prime}-\omega_{1}=\cdots=\omega_{K}^{\prime}-\omega_{K}=K_{K} *\left(I_{q K}-I_{q K}^{\prime}\right)=H .
$$

As can be seen from the above equation, in order to make the reactive current accurately share the load in proportion to the capacity, it only needs to set the corresponding droop coefficient in proportion.

When the system impedance is pure resistance, equation (10) can be simplified as

$$
\left\{\begin{array}{l}
I_{d K}=\frac{E_{K} \cos \phi_{K}-U}{r_{K}} \approx \frac{E_{K}-U}{r_{K}}, \\
I_{q K}=\frac{E_{K} \sin \phi_{K}}{r_{K}} \approx \frac{E_{K} \phi_{K}}{r_{K}} .
\end{array}\right.
$$

According to formulas (7) and (14), the control block diagrams of active current and voltage, reactive current, and angular frequency of the system can be drawn. According to the control block diagram, the output active current and reactive current of the inverter can be obtained:

$$
\left\{\begin{array}{l}
I_{d K}(s)=\frac{E_{K}^{\prime}-U+L * I_{q K}^{\prime}}{r_{K}+L}, \\
I_{q K}(s)=\frac{E_{K}\left(\omega^{\prime}(s)-\omega_{K}(s)+L * I_{q K}^{\prime}\right)}{s * r_{K}+L * E_{K}} .
\end{array}\right.
$$

According to equation (3), it can be seen that the static difference in the steady-state condition will be suppressed to a certain extent because there is an integral link in the sag control of reactive current. Since the active current has no regulating function of integral, it is difficult to realize the equal division of the active current.

Therefore, it can be considered to calculate the difference between the voltage amplitude of its own output and the voltage amplitude at the common connection point collected. After that, the difference is adjusted through the PI regulator. Finally, the output variable of the PI regulator is added to the voltage output expression (17) of the original droop governing equation:

$$
E=A_{1}=A_{2}=\cdots=A_{n}=V .
$$

Thus, the adaptive control method can be obtained, as shown in Figure 5:

$$
S=\sqrt{S_{1}^{2}+S_{2}^{2}}
$$

where $S_{1}$ and $S_{2}$ are the apparent capacity of harmonic and reactive currents in the detected load current $L_{\text {f.abc }}$, respectively. It can be calculated from equations (18) and (19), respectively:

$$
\begin{aligned}
& S_{1}^{2}=\left(U_{d} I_{\mathrm{f} d}+U_{q} I_{f q}\right)^{2}+\left(U_{d} I_{1 d}-U_{q} I_{1 q}\right)^{2}, \\
& S_{2}^{2}=\left(U_{q} I_{2 d}-U_{d} I_{2 q}\right)^{2},
\end{aligned}
$$

where 1, 2, and 3 are, respectively, the effective value components of grid voltage, reactive current, and harmonic current in the selected coordinate system. The calculation formula of effective value is as follows:

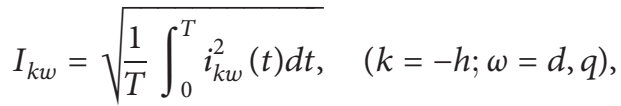

where $T=2 \pi / \omega$ is the power frequency period of the power grid, and $\omega$ is the fundamental wave angular frequency of the power grid.

Instead of calculating the apparent capacity of the harmonic current, an approximate and simple method will be found.

In the ideal case, the grid voltage without distortion and three-phase asymmetry can be expressed as 


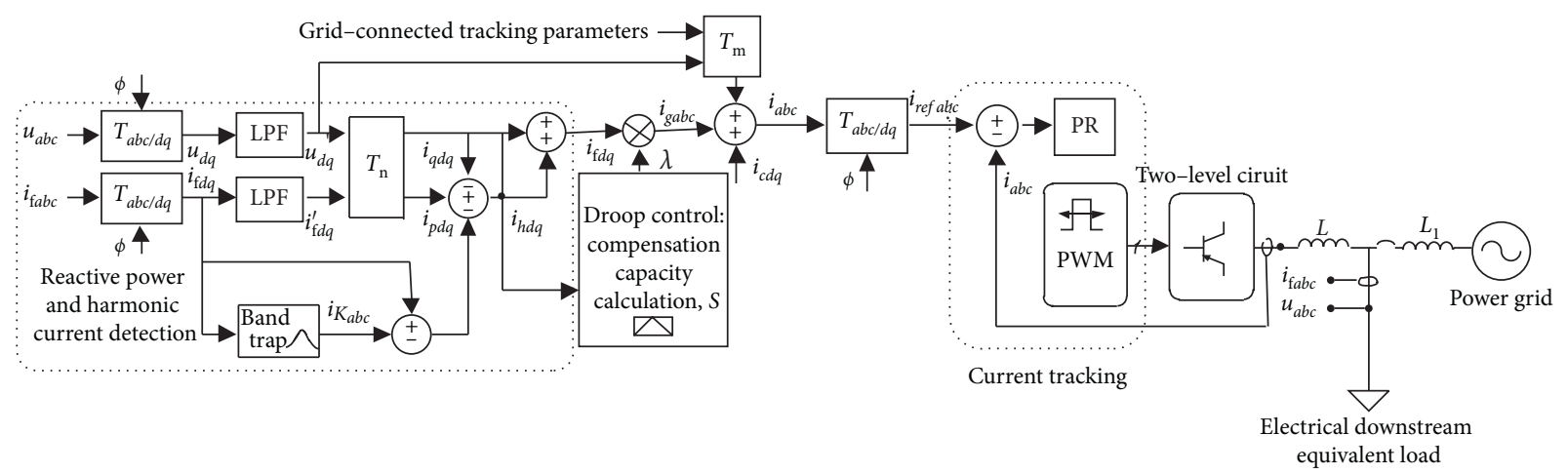

Figure 5: Adaptive control strategy scheme.

$$
\left\{\begin{array}{l}
U_{a}=U_{m} \sin \left(\phi-30^{\circ}\right), \\
U_{b}=U_{m} \sin \left(\phi-30^{\circ}-120^{\circ}\right), \\
U_{c}=U_{m} \sin \left(\phi-30^{\circ}+120^{\circ}\right) .
\end{array}\right.
$$

The phase of grid voltage is $0^{\circ}$, so the line voltage can be expressed as

$$
\left\{\begin{array}{l}
U_{a b}=\sqrt{3} U_{m} \sin \phi, \\
U_{b c}=\sqrt{3} U_{m} \sin \left(\phi-120^{\circ}\right), \\
U_{c a}=\sqrt{3} U_{m} \sin \left(\phi+120^{\circ}\right) .
\end{array}\right.
$$

Furthermore, the analytical expression of the threephase uncontrolled rectifier nonlinear load current can be obtained as follows:

$$
\begin{aligned}
& i_{\mathrm{f} a}= \begin{cases}0 & \phi \in\left[0,60^{\circ}\right) \cup\left[180^{\circ}, 240^{\circ}\right), \\
\frac{u_{a b}}{R} & \phi \in\left[60^{\circ}, 120^{\circ}\right), \\
\frac{u_{a c}}{R} & \phi \in\left[120^{\circ}, 180^{\circ}\right), \\
\frac{u_{a b}}{R} & \phi \in\left[240^{\circ}, 300^{\circ}\right), \\
\frac{u_{a c}}{R} & \phi \in\left[300^{\circ}, 360^{\circ}\right),\end{cases} \\
& i_{\mathrm{f} b}= \begin{cases}\frac{u_{b c}}{R} & \phi \in\left[0,60^{\circ}\right), \\
\frac{u_{b a}}{R} & \phi \in\left[60^{\circ}, 120^{\circ}\right), \\
0 & \phi \in\left[120^{\circ}, 180^{\circ}\right) \cup\left[300^{\circ}, 360^{\circ}\right), \\
\frac{u_{b c}}{R} & \phi \in\left[180^{\circ}, 240^{\circ}\right), \\
\frac{u_{b a}}{R} & \phi \in\left[240^{\circ}, 300^{\circ}\right),\end{cases}
\end{aligned}
$$

$$
i_{\mathrm{f} c}= \begin{cases}\frac{u_{c b}}{R} & \phi \in\left[0,60^{\circ}\right), \\ 0 & \phi \in\left[60^{\circ}, 120^{\circ}\right) \cup\left[240^{\circ}, 300^{\circ}\right), \\ \frac{u_{c a}}{R} & \phi \in\left[120^{\circ}, 180^{\circ}\right), \\ \frac{u_{c b}}{R} & \phi \in\left[180^{\circ}, 240^{\circ}\right), \\ \frac{u_{c a}}{R} & \phi \in\left[300^{\circ}, 360^{\circ}\right) .\end{cases}
$$

The following formula can be obtained:

$$
\begin{aligned}
{\left[\begin{array}{c}
i_{f d} \\
i_{f q}
\end{array}\right]=T_{a b c / d q}\left[\begin{array}{c}
i_{f a} \\
i_{f b} \\
i_{f c}
\end{array}\right]=\left\{\begin{array}{l}
i_{f d q 1}, \phi \in\left[0,60^{\circ}\right) \cup\left[180^{\circ}, 240^{\circ}\right) \\
i_{f d q 2}, \phi \in\left[60^{\circ}, 120^{\circ}\right) \cup\left[240^{\circ}, 300^{\circ}\right), \\
i_{f d q 3}, \phi \in\left[120^{\circ}, 180^{\circ}\right) \cup\left[300^{\circ}, 360^{\circ}\right)
\end{array}\right.} \\
i_{f d q 1}=\frac{-\sqrt{6} U_{m}}{2 R}\left[\begin{array}{l}
\cos \left(\theta-\phi-60^{\circ}\right)-\cos \left(\theta+\phi+60^{\circ}\right) \\
\sin \left(\theta+\phi+60^{\circ}\right)+\sin \left(\theta+\phi-60^{\circ}\right)
\end{array}\right], \\
i_{\mathrm{f} d q 2}=\frac{-\sqrt{6} U_{m}}{2 R}\left[\begin{array}{l}
-\sin \left(\theta+\phi+30^{\circ}\right)-\sin \left(\theta-\phi-30^{\circ}\right) \\
-\cos \left(\theta+\phi+30^{\circ}\right)+\cos \left(\theta+\phi-30^{\circ}\right)
\end{array}\right], \\
i_{\mathrm{f} d q 3}=\frac{-\sqrt{6} U_{m}}{2 R}\left[\begin{array}{l}
\sin \left(-\theta+\phi+60^{\circ}\right)+\cos (\theta+\phi) \\
\cos \left(-\theta+\phi+60^{\circ}\right)-\sin (\theta+\phi)
\end{array}\right] .
\end{aligned}
$$

If oriented by grid voltage $\theta=\phi-30^{\circ}$, the DQ axis component of large grid voltage $U_{d q}$ can be expressed as

$$
\left[\begin{array}{c}
U_{d} \\
U_{q}
\end{array}\right]=T_{a b c / d q}\left[\begin{array}{c}
U_{a} \\
U_{b} \\
U_{c}
\end{array}\right]=\frac{\sqrt{6}}{2}\left[\begin{array}{c}
0 \\
-U_{m}
\end{array}\right] .
$$


At this time, equations (25)-(27) can be simplified into

$$
\begin{aligned}
& i_{\mathrm{f} d q 1}=\frac{-\sqrt{6} U_{m}}{2 R}\left[\begin{array}{c}
-\cos \left(2 \phi+30^{\circ}\right) \\
1+\sin \left(2 \phi+30^{\circ}\right)
\end{array}\right], \\
& i_{\mathrm{fdq2}}=\frac{-\sqrt{6} U_{m}}{2 R}\left[\begin{array}{c}
-\sin (2 \phi) \\
1-\cos (2 \phi)
\end{array}\right], \\
& i_{\mathrm{f} d q 3}=\frac{-\sqrt{6} U_{m}}{2 R}\left[\begin{array}{c}
\cos \left(2 \phi-30^{\circ}\right) \\
1-\sin \left(2 \phi-30^{\circ}\right)
\end{array}\right] .
\end{aligned}
$$

According to the analysis results of equations (29)-(31), the average value of load current in the axial component is

$$
\begin{aligned}
I_{f d}^{\prime} & =\frac{1}{T} *\left[\int_{0}^{T} i_{\mathrm{fd}}(t) d t\right]=\frac{1}{2 \pi} \div\left[\int_{0}^{180^{\circ}} i_{f d}(\phi) d \phi\right] \\
& =-\frac{\sqrt{6} U_{m}}{2 R} * \frac{3}{\pi} \int_{0}^{60^{\circ}}\left[-\cos \left(2 \phi+30^{\circ}\right)\right] d \phi=0, \\
I_{L d}^{\prime} & =\frac{1}{T} *\left[\int_{0}^{T} i_{\mathrm{fq}}(t) d t\right]=\frac{1}{2 \pi} \div\left[\int_{0}^{180^{\circ}} i_{f q}(\phi) d \phi\right] \\
& =\frac{3}{\pi} * \int_{0}^{60^{\circ}}\left[1+\sin \left(2 \phi+30^{\circ}\right)\right] d \phi \\
& =-\frac{\sqrt{6} U_{m}}{2 R} * \frac{1+3}{\pi} * \frac{\sqrt{3}}{2} .
\end{aligned}
$$

Similarly, the maximum DQ axis component of the harmonic current can be expressed as

$$
\begin{aligned}
& i_{h d \text {.max }}=\frac{\sqrt{6} U_{m}}{2 R} * \cos 30^{\circ}, \\
& i_{\text {hq.max }}=-3 \frac{\sqrt{6} U_{m}}{2 R} *\left[1+\sin 60^{\circ}\right]-I_{f}{ }^{\prime} .
\end{aligned}
$$

In addition, according to the definition of equation (21), the effective values of the DQ axis component of the harmonic current can be obtained as follows:

$$
\begin{aligned}
& I_{h d}=\sqrt{\frac{1}{T} * \int_{0}^{T}\left[i_{f d}(t)-I_{f d}^{\prime}\right]^{2} d t}=\sqrt{\frac{1}{T} \int_{0}^{360^{\circ}}\left[i_{f d}(\phi)-I_{f d}^{\prime}\right]^{2} d \phi} \\
& =\sqrt{\frac{6}{2 \pi} * \int_{0}^{60^{\circ}}\left[i_{f d}(\phi)-I_{f d}^{\prime}\right]^{2} d \phi}=\frac{\sqrt{6} U_{m}}{2 R} * \sqrt{\frac{1}{2}-\frac{3}{\pi} * \frac{\sqrt{3}}{8}}, \\
& I_{h q}=\sqrt{\frac{1}{T} \int_{0}^{T}\left[i_{f q}(t)-I_{f d}^{\prime}\right]^{2} d t}=\sqrt{\frac{1}{T} * \int_{0}^{360^{\circ}}\left[i_{f q}(\phi)-I_{f d}^{\prime}\right]^{2} d \phi} \\
& =\sqrt{\frac{6}{2 \pi} * \int_{0}^{60^{\circ}}\left[i_{f q}(\phi)-I_{f q}^{\prime}\right]^{2} d \phi}=\frac{\sqrt{6} U_{m}}{2 R} * \sqrt{\frac{5}{4}+\frac{3}{\pi} * \frac{3}{8}-\frac{3}{2}} .
\end{aligned}
$$

Taking $U_{m}=128 \mathrm{~V}$ and $R=15 \Omega$ as an example, the effective values of $i_{h d}$ and $i_{h q}$ in a period T can be calculated as $5.65 \mathrm{~A}$ and $1.63 \mathrm{~A}$, respectively; The maximum $i_{h d q}$ and $i_{\text {hdmax }}$ of $i_{\text {hqmax }}$ can also be calculated to be 9.05 A and $2.85 \mathrm{~A}$, respectively.

According to the definition, the autocorrelation waveform coefficients $n_{d}$ and $n_{q}$ of the harmonic load current in axis $\mathrm{D}$ and axis $\mathrm{Q}$ are

$$
\left\{\begin{array}{l}
n_{d}=\frac{I_{h d}}{I_{h d \cdot \max }}, \\
n_{q}=\frac{I_{h q}}{I_{h q \cdot \max }} .
\end{array}\right.
$$

where - and $=$ are the instantaneous maximum values of the harmonic current under the $\mathrm{D}$ axis and $\mathrm{Q}$ axis, respectively.

It should be noted that the control strategy compensates the detected harmonic and reactive currents of each distributed generation system in a certain proportion and only apportions the reactive and harmonic currents according to its own capacity.

2.3. Simulation and Experiment. In order to verify the correctness and feasibility of the proposed control strategy, simulation and experimental verification are carried out. The test conditions are shown in Figure 6: The test system consists of two distributed generation systems, and a $5.8 \mathrm{GHz}$ wireless network bridge is placed in the simulation monitoring center of the distributed generation system. Among them, the distance between distributed generation system 1 and distributed generation system 2 is about $1-1.5 \mathrm{~km}$, and the distance between distributed generation system 2 and the monitoring center is about $2 \mathrm{~km}$. The parameters of each part are shown in Table 1.

\subsubsection{Simulation}

(1) Performance Test and Analysis of Wireless Communication Network. Run the test software program, and finally get the test results as shown in Table 2 and Figures 7 and 8 . The test data statistics can be seen in Table 2. RSSI is the abbreviation of Received Signal Strength Indication, which refers to the Received Signal Strength. Figures 7 and 8, respectively, show the throughput and response time of wireless network data transmission. It is found that its throughput ranges from 0.689 to 14.321 . The response time is between 0.111 and 0.251 . It can be seen that the communication effect of this wireless network can basically meet the communication requirements of a small number of distributed power sources, and there is enough allowance, and the packet loss rate is small, far less than $2 \%$. The overall performance of the network meets the application requirements.

(2) The Simulation Analysis of Active Synchronization Control Strategy. In order to verify the effectiveness of the proposed control scheme, firstly, the simulation model was built according to the distributed power system structure shown in Figure 6, and the parameters of each part are shown in Table 1. And then the simulation is carried out. 


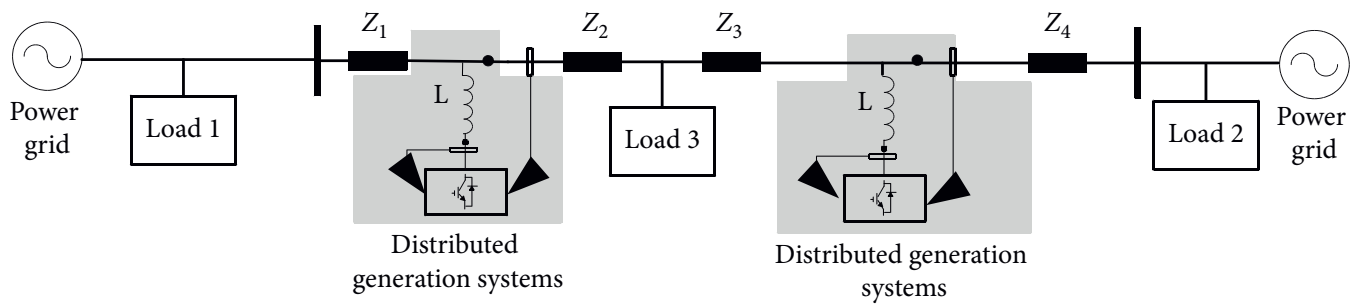

FIGURE 6: Simplified structure diagram of the distributed power system.

TABLE 1: Parameters of the distributed power system.

\begin{tabular}{lcc}
\hline & Rated voltage/frequency & Rated active/reactive power frequency \\
\hline Inverter & $220 \mathrm{~V} / 50 \mathrm{~Hz}$ & $5 \mathrm{~kW} / 0 \mathrm{kvar}$ \\
Synchronous generator & $220 \mathrm{~V} / 50 \mathrm{~Hz}$ & $10 \mathrm{~kW} / 0 \mathrm{kvar}$ \\
Load 1 & $220 \mathrm{~V} / 50 \mathrm{~Hz}$ & $5 \mathrm{~kW} / 0 \mathrm{kvar}$ \\
Load 2 & $220 \mathrm{~V} / 50 \mathrm{~Hz}$ & $10 \mathrm{~kW} / 0 \mathrm{kvar}$ \\
Load 3 & $220 \mathrm{~V} / 50 \mathrm{~Hz}$ & $5 \mathrm{~kW} / 4 \mathrm{kvar}$ \\
\hline
\end{tabular}

TABLE 2: Performance test results of the wireless communication network.

\begin{tabular}{lccccc}
\hline & RSSI1 & Test terminal & Throughput (Mbps) & Response time (s) & Packet loss rate \\
\hline RSSI1-test terminal & $-64 \mathrm{dBm}$ & $-65 \mathrm{dBm}$ & $0.689 \sim 14.321$ & $0.111 \sim 0.251$ & $2 \%(1169)$ \\
\hline
\end{tabular}

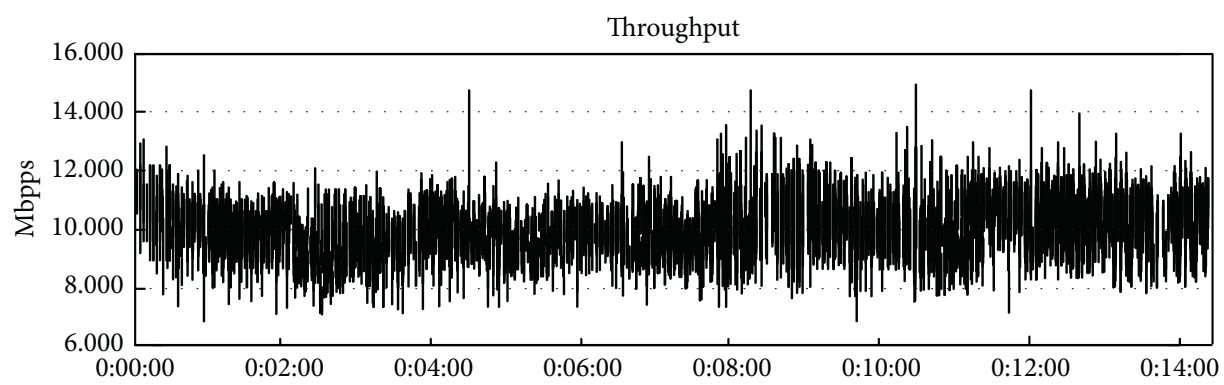

FIGURE 7: The testing results of wireless communication network throughput.

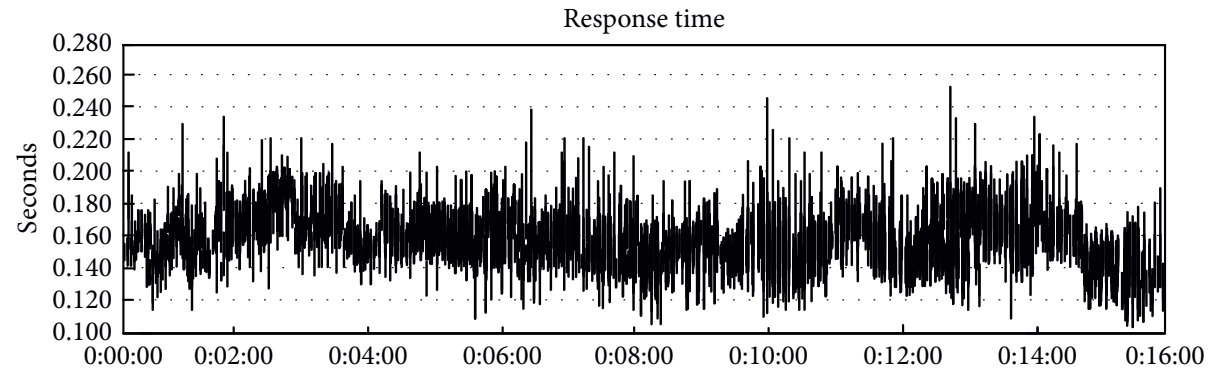

FIgURE 8: Test results of response time of the wireless communication network.

The experimental process is shown in Figure 9: at the initial moment, the distributed generation system is connected to the large power grid. After the sudden load increase, the amplitude and frequency of the system side decrease. The amplitude and frequency of the slip signal are increased to the rated output, and the output power reaches the rated demand of the load after adjusting the slip signal with active synchronous regulation. The distributed generation system can keep the synchronous operation with the large grid, and the simulation verifies the correctness of the active synchronous control scheme proposed in this paper. 


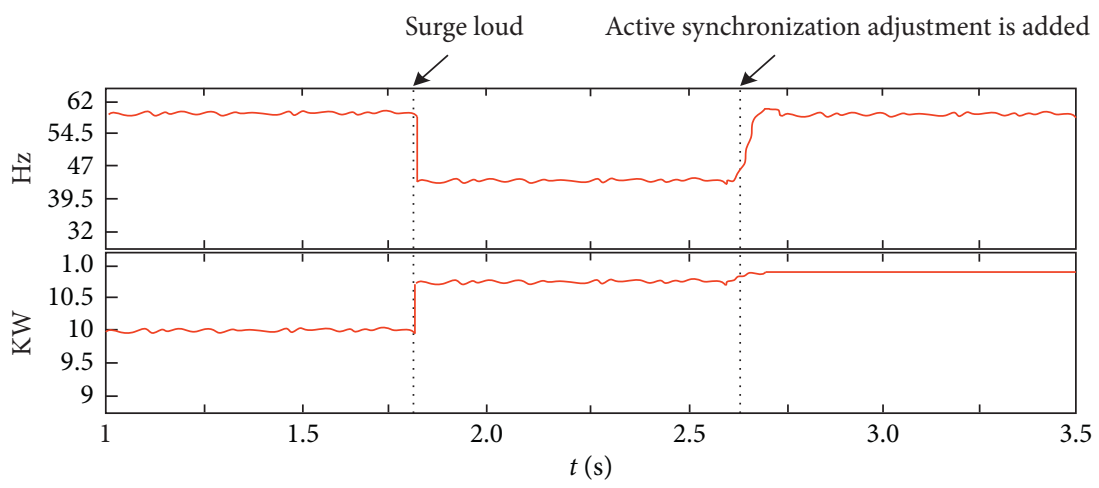

FIGURE 9: Frequency/active power variation waveform.

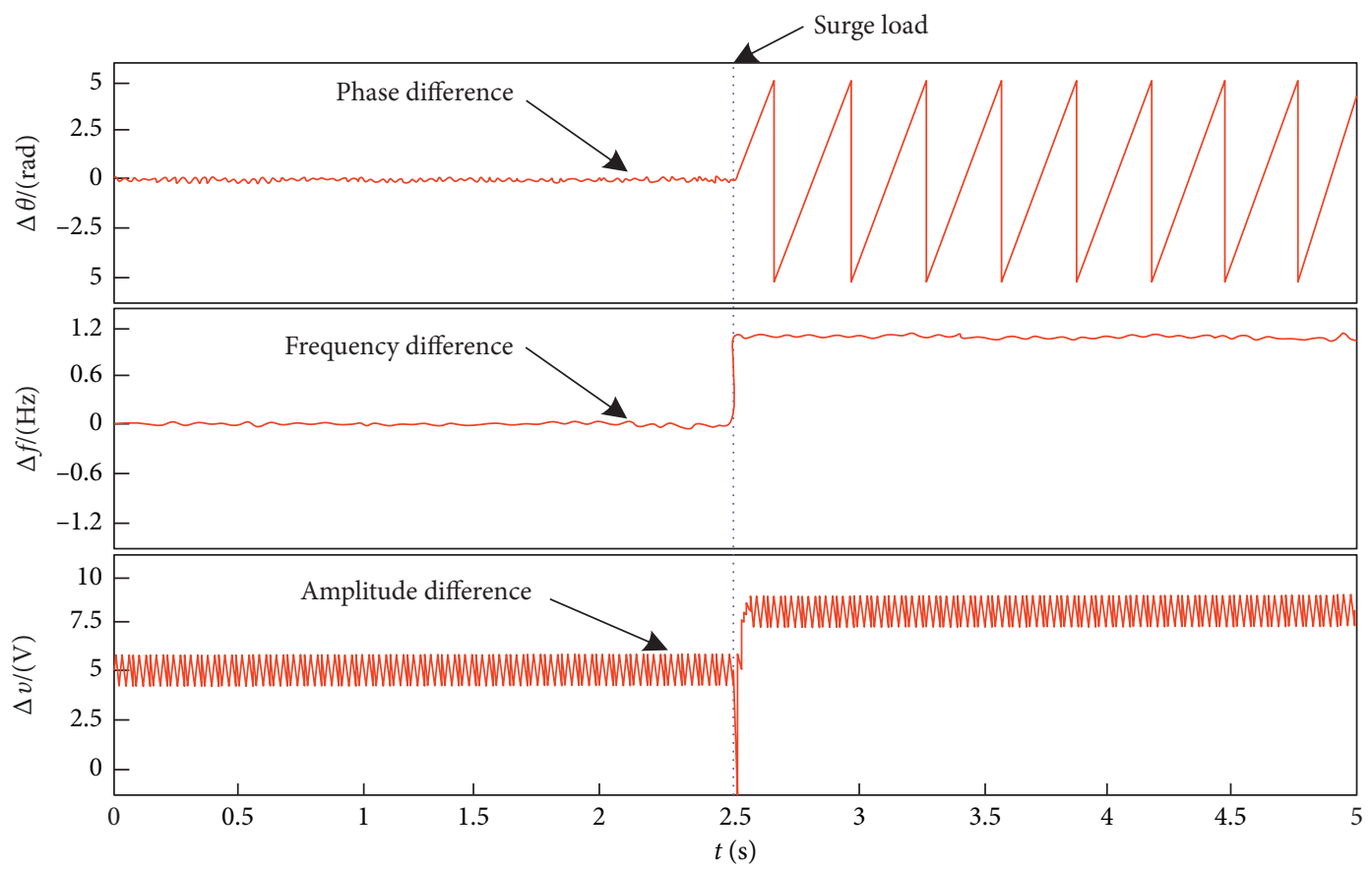

Figure 10: Voltage slip signal without active synchronization regulation.

2.3.2. Experiment. In order to further verify the correctness of the scheme, the experiment is carried out on the experimental platform. The background of the experiment is shown in the previous section.

At the beginning, the output voltage of the inverter is the same as the voltage information of the large grid side. At a certain moment, Load 3 is suddenly added. After that, the slip signal is detected because slip signal is an important index for the central controller to determine whether the side voltage information of distributed generation system meets the grid-connection standard. As the most common slip signal detection method, the zero-crossing detection method is simple in principle and easy to implement. However, it has the disadvantages of long detection time and weak antijamming ability. Using the improved zero-crossing detection method proposed in this paper, the slip signal detection unit can quickly and accurately obtain the slip signal between the distributed generation system and the large power grid. Finally, the slip signal waveform as shown in Figure 10 is obtained.

As can be seen from Figure 11, slip signal detection unit detects that the amplitude difference of voltage on both sides of the distributed power system and large power grid is about $5 \mathrm{~V}$, the frequency difference is about $0.5 \mathrm{~Hz}$, and the phase difference is the periodic transformation of $T=2$ s. Obviously, the voltage amplitude on the side of the distributed generation system is greatly different from that on the side of large power grid, which does not meet the grid-connection standard and will still produce a large impulse current. Therefore, it is impossible to reconnect the distributed generation system with the large power grid, so the slip signal needs to be synchronously adjusted actively.

Figure 10 shows the voltage slip waveform without active synchronous adjustment. It can be seen that the voltage slip has changed periodically. Close the distributed power grid- 


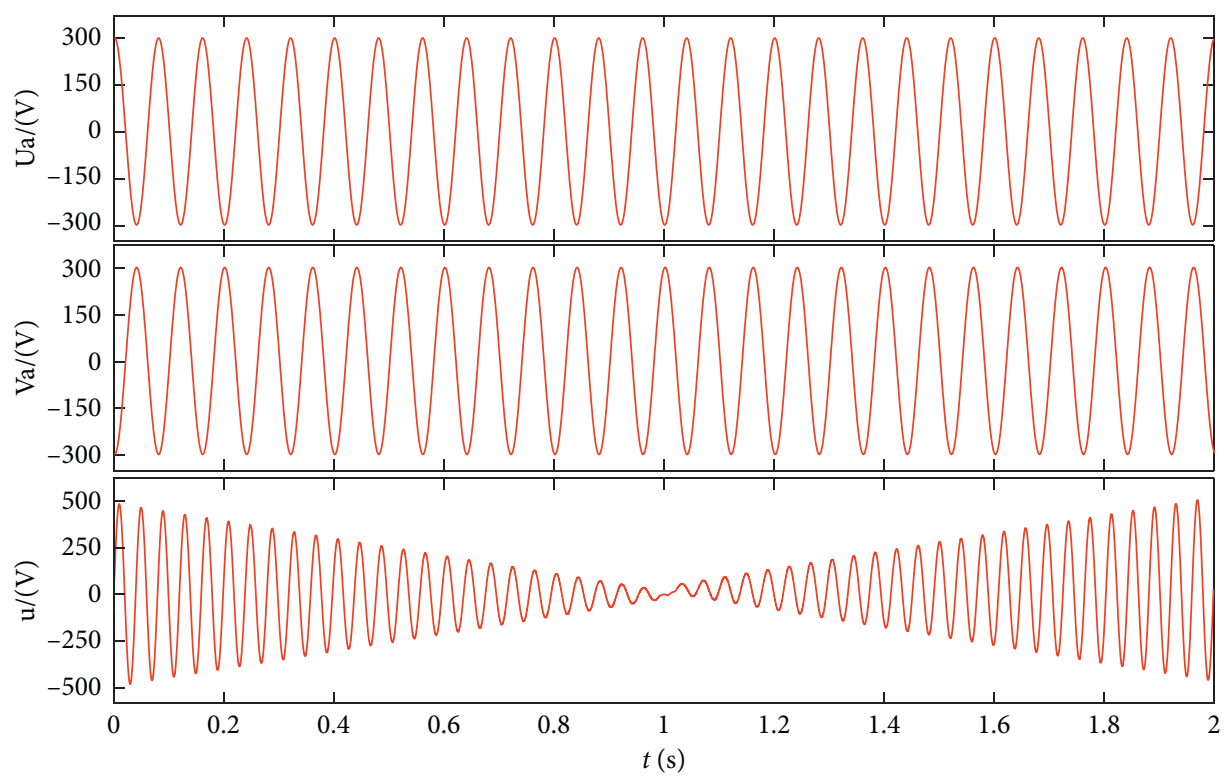

Figure 11: The slip signal generated after a sudden increase in load.

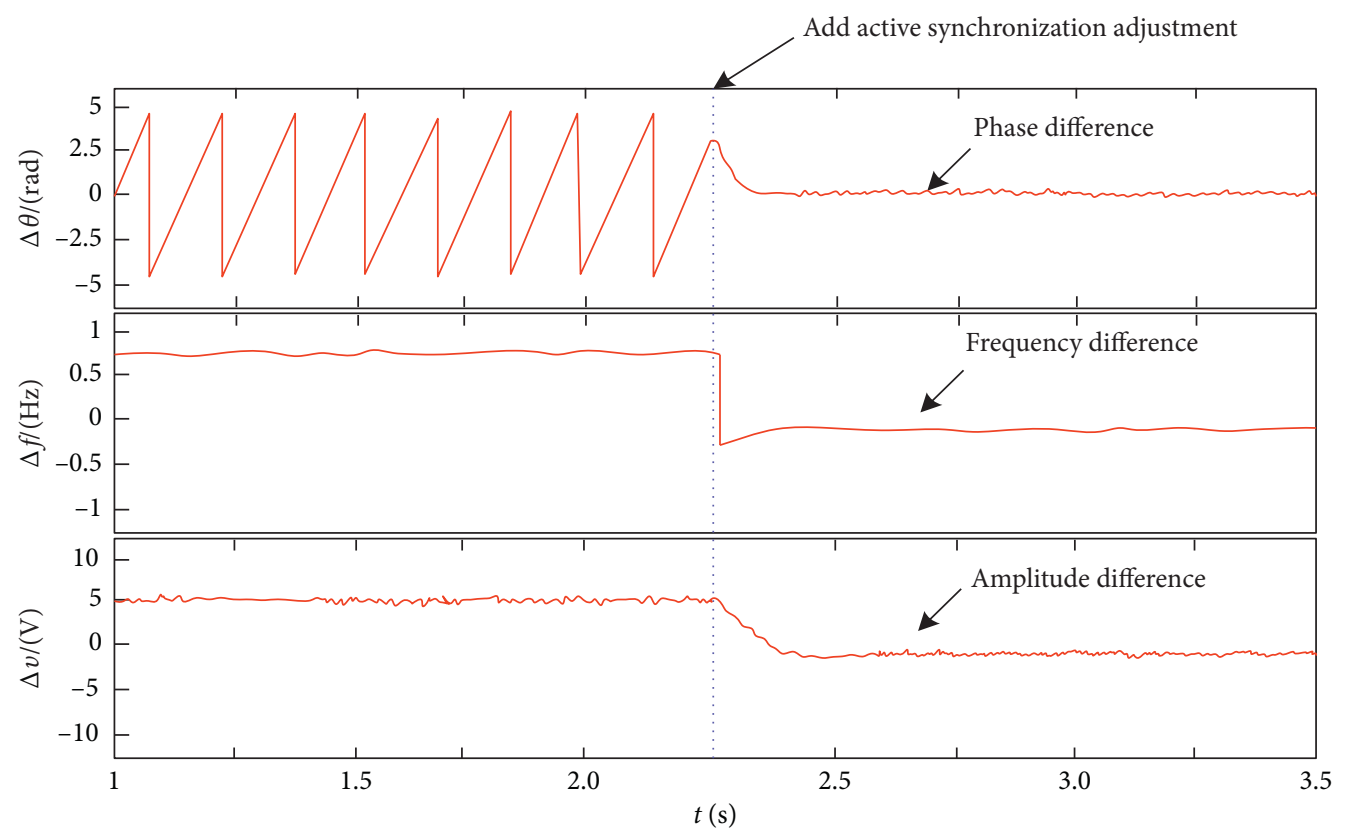

FIGURE 12: Voltage slip signal with active synchronization regulation.

connected switch near $1.7 \mathrm{~s}$, because at this time, the voltage slip is the minimum and the current impact is the minimum. However, if you miss this moment, the voltage slip becomes larger and you need to wait again. The smaller the frequency difference is, the longer the waiting time will be, and then the moment with the smallest voltage slip will appear again. When $t=1.8 \mathrm{~s}$, the local controller simultaneously adjusts the voltage amplitude, phase, and frequency of the distributed power system. The variation of the detected voltage slip signal is shown in Figure 12, and the A-phase voltage and slip waveform at PCC point and both sides of the large power grid are shown in Figure 13.
As can be seen from Figure 12, after active adjustment, the amplitude, frequency, and phase difference all decreased to 0 after about $1 \mathrm{~s}$. During active regulation, the local receiver first adjusts the local output voltage after receiving the regulated signal. Its essence is to change the output voltage amplitude and frequency by shifting the sag characteristic curve. The voltage information at the common coupling point of the distributed generation system changes with the change of its output voltage and finally realizes the synchronization with the large grid voltage.

It can be seen from Figure 13 that, at the corresponding moment, the side voltage of the distributed 


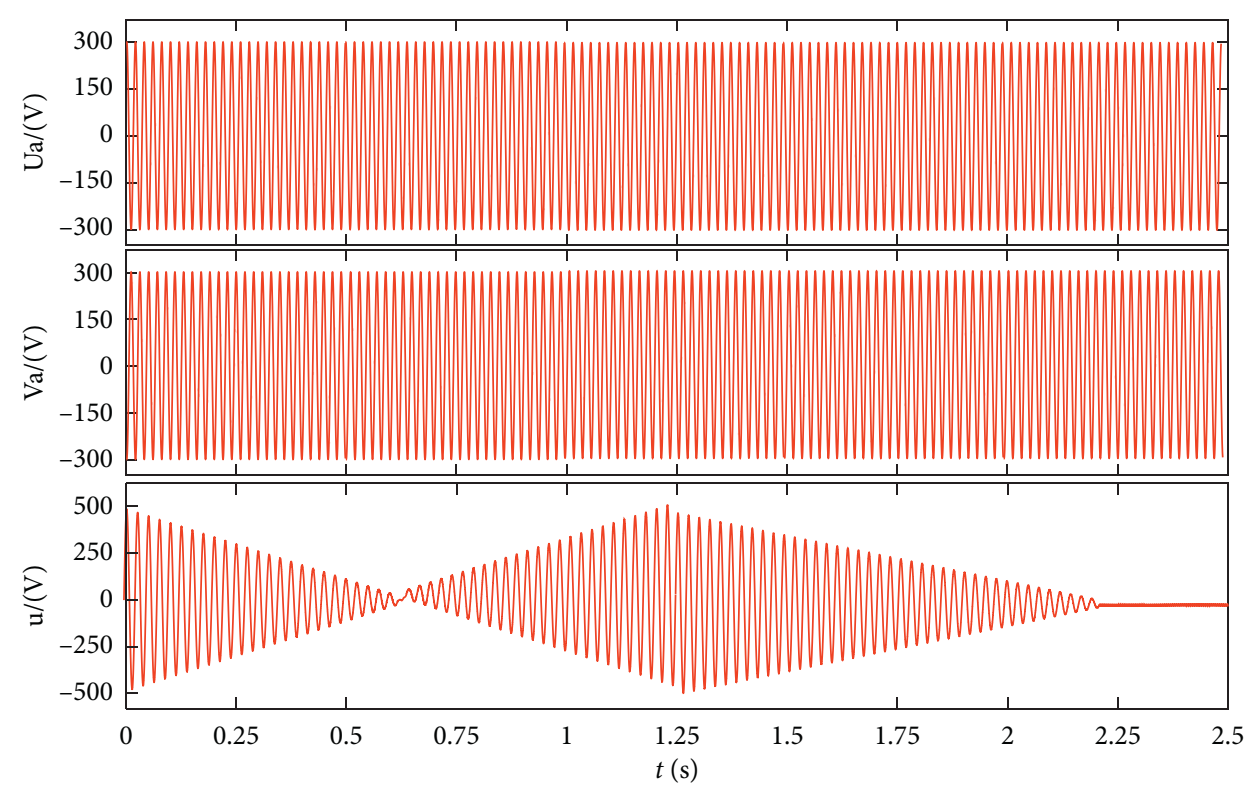

FIGURE 13: The A-phase voltage and slip waveform after active synchronous adjustment were added.

power system fully tracks the voltage on the side of the large grid. It shows that after active synchronization regulation, the voltage of the distributed power system side can be synchronized with the large power grid. The correctness of the proposed active synchronous control scheme is verified.

\section{Conclusions}

This paper studies the synchronization problem between the distributed power system and large power grid and proposes an active synchronization control scheme which can be applied to the distributed power grid-connection system. Under the background of hierarchical control strategy, the regulation signal is sent to the local control layer through the mobile network at the central control layer of the distributed power system, and then the output voltage information of the distributed power plant is changed by shifting the pendent characteristic curve, and then the voltage information at the PCC point is changed until it is synchronized with the voltage information at the large grid side. Finally, simulation and experimental verification are carried out. The results show that after a period of adjustment, the voltage information at the common coupling point of the distributed power system basically matches and synchronizes with the voltage information at both ends of the large power grid, which verifies the correctness and effectiveness of the active synchronous control scheme.

\section{Data Availability}

The data used in the research of this article are available from the corresponding author upon request.

\section{Conflicts of Interest}

The authors declare that there are no conflicts of interest regarding the publication of this paper.

\section{Acknowledgments}

This study was funded by Scientific Research Fund Project of Education Department of Liaoning Province (project no. JL2015); Liaoning Province Science and Technology Planning Project, Industrial Key Problems and Industrialization Guidance Plan (project no. 2019JH8/10100065); and Research Project of Shenyang Institute of Engineering (project no. LGQN-1906).

\section{References}

[1] T. Mai, D. Steinberg, J. Logan, D. Bielen, K. Eurek, and C. McMillan, "An electrified future: initial scenarios and future research for US energy and electricity systems," IEEE Power and Energy Magazine, vol. 16, no. 4, pp. 34-47, 2018.

[2] H. Gao, C. Liu, Y. Li, and X. Yang, "V. 2V. R.: Reliable hybridnetwork-oriented $\mathrm{V} 2 \mathrm{~V}$ data transmission and routing considering RSUs and connectivity probability," IEEE Transactions On Intelligent Transportation Systems (T-ITS), vol. 2020, pp. 1-14, 2020.

[3] M. Ashgari, S. Yousefi and D. Niyato, An analysis of services bundles operators with free services included," IEEE Transactions on Mobile Computing, vol. 19, no. 8, pp. 1789-1803, 2019.

[4] H. Gao, W. Huang, and Y. Duan, "The cloud-edge-based dynamic reconfiguration to service workflow for mobile ecommerce environments," ACM Transactions on Internet Technology, vol. 21, no. 1, p. 1, 2021.

[5] L. Herrera López, "A closer look at direct carrier billing: identifying the determinants of purchase and use of a mobile game," International Journal of Online Marketing (IJOM), vol. 10, 2020.

[6] X. Ma, H. Gao, H. Xu, and M. Bian, "An IoT-based task scheduling optimization scheme considering the deadline and cost-aware scientific workflow for cloud computing," EURASIP Journal on Wireless Communications and Networking, vol. 2019, no. 1, 2019. 
[7] C. Shao and J. Zhang, "Research of the multi-way connectivity probability for platoon-based vehicle-to-infrastructure communication network," The Journal of China Universities of Posts and Telecommunications, vol. 23, no. 1, pp. 1-7, 2016.

[8] H. Gao, L. Kuang, Y. Yin, B. Guo, and K. Dou, "Mining consuming behaviors with temporal evolution for personalized recommendation in mobile marketing apps," Mobile Networks and Applications, vol. 25, no. 4, pp. 1233-1248, 2020.

[9] A. Hoke, J. Giraldez, B. Palmintier et al., "Setting the smart solar standard: collaborations between Hawaiian electric and the national renewable energy laboratory," IEEE Power and Energy Magazine, vol. 16, no. 6, pp. 18-29, 2018.

[10] X. Yang, S. Zhou, and M. Cao, "An approach to alleviate the sparsity problem of hybrid collaborative filtering based recommendations: the product-attribute perspective from user reviews," Mobile Networks and Applications, vol. 25, no. 2, pp. 376-390, 2020.

[11] J. Dai, W. Yang, J. Cao, D. Liu, and X. Long, "Ageing assessment of a wind turbine over time by interpreting wind farm SCADA data," Renewable Energy, vol. 116, pp. 199-208, 2018.

[12] Z. Wang, B. Chen, J. Wang, and C. Chen, "Networked microgrids for self-healing power systems," IEEE Transactions on Smart Grid, vol. 7, no. 1, pp. 310-319, 2017.

[13] T. Apanasevic, N. Arvidsson, J. N. Markendahl, and J. Markendahl, Mobile payments: a proposal for a contextoriented approach based on socio-technical theory," Journal of Innovation Management, vol. 6, no. 3, pp. 40-97, 2018.

[14] R. R. Arvidsson, V. B. Borghate, P. M. Meshram, H. M. Suryawanshi, and S. Sabyasachi, "A three-phase hybrid cascaded modular multilevel inverter for renewable energy environment," IEEE Transactions on Power Electronics, vol. 32, no. 2, pp. 1070-1087, 2017.

[15] W. Xuan, Z. Pan, B. Wang, H. Sun, and Q. Guo, "Review on virtual power plant resource aggregation and collaborative regulation using cloud-tube-edge-end architecture," Journal of Global Energy Interconnection, vol. 3, no. 6, pp. 2096-5125, 2020.

[16] A. S. Bakare, A. Owusu, and D. T. Abdurrahaman, "The behavior response of the Nigerian youths toward mobile advertising: an examination of the influence of values, attitudes and culture," Cogent Business and Management, vol. 4, no. 1, 2017.

[17] J. Jia, G. Yang, and A. H. Nielsen, "A review on grid-connected converter control for short-circuit power provision under grid unbalanced faults," IEEE Transactions on Power Delivery, vol. 33, no. 2, pp. 649-661, 2018.

[18] A. Calle-Prado, S. Alepuz, J. Bordonau, J. Nicolas-Apruzzese, P. Cortés, and J. Rodriguez, "Model predictive current control of grid-connected neutral-point-clamped converters to meet low-voltage ride-through requirements," IEEE Transactions on Industrial Electronics, vol. 62, no. 3, pp. 1503-1514, 2015.

[19] H. Ren, R. Meng, R. Dou, L. Wang, and J. Liu, "Design of optimal control system of 'source-grid-load-storage' based on 5G network," Electric Power ICT, vol. 18, no. 12, pp. 23-28, 2020.

[20] R. Li, "Idea of random power supply plug and play based on cloud-layer-terminal three layer architecture," Power System Protection and Control, vol. 44, no. 7, 2016.

[21] L. Tan, B. Wu, S. Rivera, and V. Yaramasu, "Comprehensive DC power balance management in high-power three-level DC-DC converter for electric vehicle fast charging," IEEE Transactions on Power Electronics, vol. 31, no. 1, pp. 89-100, 2016.
[22] L. Tan, B. Wu, V. Yaramasu, S. Rivera, and X. Guo, "Effective voltage balance control for bipolar-DC-bus fed EV charging station with three-level DC-DC fast charger," IEEE Transaction on Industrial Electronics, vol. 63, no. 7, pp. 4031-4041, 2016.

[23] L. Yang, Y. Qi, W. Lingling, and Z. Lu, "A distribution network fault recovery studyon the dynamic alliance of mobile multi-agent," Transactions of China Electrotechnical society, vol. 31, no. 8, 2016.

[24] C. Yang, J. Liu, Y. Zeng, and G. Xie, "Real-time condition monitoring and fault detection of components based on machine-learning reconstruction model," Renewable Energy, vol. 133, pp. 433-441, 2019.

[25] J. Lei, C. Liu, and D. Jiang, "Fault diagnosis of wind turbine based on long short-term memory networks," Renewable Energy, vol. 133, pp. 422-432, 2019.

[26] A. Jain, A. Mani, and A. S. Siddiqui, "Network architecture for demand response implementation in smart grid," International Journal of System Assurance Engineering and Management, vol. 10, no. 2, pp. 1389-1402, 2019.

[27] A. S. Nair, T. Hossen, M. Campion et al., "Multi-agent systems for resource allocation and scheduling in a smart grid," Technology and Economics of Smart Grids and Sustainable Energy, vol. 3, no. 1, pp. 3-15, 2018.

[28] K. Filsoof and P. W. Lehn, "A bidirectional multiple-input multiple-output modular multilevel DC-DC converter and its control design," IEEE Transactions on Power Electronics, vol. 31, no. 4, pp. 2767-2779, 2016.

[29] J. T. Tahadray, C. Yongquan, and D. Allah, "Secure selfhealing group key distribution scheme with constant storage for SCADA systems in smart grid," Wireless Personal Communications, vol. 101, no. 3, pp. 1749-1763, 2018.

[30] H. B. Cheng, J. B. Kang, X. Wang et al., "A self-healing control method of smart distribution grid based on fault-tolerance," Advanced Technology of Electrical Engineering \& Energy, vol. 37, no. 4, pp. 9-14, 2018.

[31] B. S. Torres, L. R. Ferreira, and A. R. Aoki, "Distributed intelligent system for self-healing in smart grids," IEEE Transactions on Power Delivery, vol. 33, no. 5, pp. 2394-2409, 2018.

[32] J. Jia, G. Yang, and A. H. Nielsen, "A review on grid-connected converter control for short-circuit power provision under grid unbalanced faults," IEEE Transactions on Power Delivery, vol. 33, no. 2, pp. 649-661, 2018.

[33] L. Wang, C. Lam, and M. Wong, "Analysis, control, design of a hybrid grid-connected inverter for renewable energy generation with power quality conditioning," IEEE Transactions on Power Electronics, vol. 33, no. 8, pp. 6755-6768, 2018.

[34] B. Yang, R. Liu, and X. Chen, "Fault diagnosis for a wind turbine generator bearing via sparse representation and shiftinvariant K-svd," IEEE Transactions on Industrial Informatics, vol. 13, no. 3, pp. 1321-1331, 2017.

[35] A. Zhi, C. Shen, Z. Zheng, F. Liu, X. Chang, and W. Wei, "Scenario-based analysis and probability assessment ofsubsynchronous oscillation caused by wind farms with directdriven wind generators," Journal ofModern Power Systems and Clean Energy, vol. 7, no. 2, pp. 243-253, 2019.

[36] J. G. Dedecca, S. Lumbreras, A. Ramos, R. A. Hakvoort, and P. M. Herder, "Expansion planning of the north sea offshore grid: simulation of integrated governance constraints," Energy Economics, vol. 72, pp. 376-392, 2018.

[37] U. Karaagac, J. Mahseredjian, L. Cai, and H. Saad, "Offshore wind farm modeling accuracy and efficiency in MMC-based 
multiterminal HVDC connection," IEEE Transactions on Power Delivery, vol. 32, no. 2, pp. 617-627, 2017.

[38] C. Peng, X. Song, A. Q. Huang, and I. Husain, "A mediumvoltage hybrid DC circuit breaker-Part II: ultrafast mechanical switch," IEEE Journal of Emerging and Selected Topics in Power Electronics, vol. 5, no. 1, pp. 289-296, 2017.

[39] A. Kirakosyan, E. F. El-Saadany, M. S. E. Moursi, and K. Al Hosani, "DC voltage regulation and frequency support in pilot voltage droop-controlled multiterminal HVdc systems," IEEE Transactions on Power Delivery, vol. 33, no. 3, pp. 1153-1164, 2018.

[40] E. Elbouchikhi, V. Choqueuse, Y. Amirat, M. E. H. Benbouzid, and S. Turri, "An efficient hilbert-huang transform-based bearing faults detection in induction machines," IEEE Transactions on Energy Conversion, vol. 32, no. 2, pp. 401-413, 2017. 